\title{
Proceeding
}

Supplementary Issue: Rio 2016 Olympic Games Third Anniversary Special Edition. Olympic Studies Forum, 2-3 September 2019. Federal University of Sergipe, Aracaju, Brazil

\section{Sports, the Olympic Movement and the Olympic Programme}

\author{
BRAULIO PAES-MARQUES \\ University of Peloponnese, UoP, Brazil
}

\begin{abstract}
The Olympic Programme is composed by several events, from different sports, and composes the most prominent features of the Olympic Games (McLaughlin \& Torres, 2011). The selection of sports which will illustrate the values of Olympism every four years to a worldwide audience should be made in accordance to the same philosophy, and a way to do it is to look for each sport as a set of rules and values. The aim of this essay is to address the following question: does the multiculturalism of the Olympic Programme represent the universalism propagated by the Olympic Movement? To this end, it is presented in this work the role of rules in sports, the universalism of the Olympic Movement, and the multiculturalism of the Olympic Programme. As result, it also suggests a new method of selecting sports to compose the Olympic Programme, based on the accordance of each sport's rules and values to the universalism proposed by Olympism. Keywords: Sports; Olympism; Olympic Programme.
\end{abstract}

Cite this article as:

Paes-Marques, B. (2020). Sports, the Olympic Movement and the Olympic Programme. Journal of Human Sport and Exercise, 15(1proc), S29-S35. doi:https://doi.org/10.14198//hse.2020.15.Proc1.04

Corresponding author. University of Peloponnese, UoP, Brazil.

E-mail: braulio.p.marques@gmail.com

Supplementary Issue: Rio 2016 Olympic Games Third Anniversary Special Edition. Olympic Studies Forum, 2-3 September 2019. Federal University of Sergipe, Aracaju, Brazil.

JOURNAL OF HUMAN SPORT \& EXERCISE ISSN 1988-5202

(c) Faculty of Education. University of Alicante

doi:10.14198/jhse.2020.15.Proc1.04 


\section{INTRODUCTION}

The Olympic Programme is composed by several events, from different sports, and composes the most prominent features of the Olympic Games (McLaughlin \& Torres, 2011). The selection of sports which will illustrate the values of Olympism every four years to a worldwide audience should be made in accordance to the same philosophy, and a way to do it is to look for each sport as a set of rules and values. The purpose of this essay is to present the role of rules in sports, the universalism of the Olympic Movement, and the multiculturalism of the Olympic Programme, as well as to suggest a new way of selecting Olympic sports.

\section{MATERIALS AND METHODS}

As mentioned earlier, the purpose of this work was to analyse the current Olympic Programme and its accordance to the philosophy of Olympism. The way of achieving this aim was the presumption that any sport can be described as a set of rules and values. Therefore, the research question to be addressed was: does the multiculturalism of the Olympic Programme represent the universalism propagated by the Olympic Movement?

To address this question a literature review was conducted in three steps, starting with the role of rules in sports and advancing with the universalism of the Olympic Movement and the multiculturalism of the Olympic Programme. Practical examples extracted from the most recent edition of the Summer Olympic Games, the 2016 Rio Games, were also incorporated to the research as starting points for deeper analysis of certain Olympic sports. Findings were subsequently combined and used as basis for a suggestion of a new method of selecting sports to compose the Olympic Programme.

\section{RESULTS}

This work has achieved its aim by attesting that the multiculturalism of the Olympic Programme does not represent the universalism proposed by the Olympic Movement through the philosophy of Olympism.

The three steps literature review has identified the binary classification of constitutive and regulative rules for any sport discipline, the challenge for all leading institutions of the Olympic Movement to maintain and expand its universalism, and the current situation of thick multiculturalism worldwide when it comes to the Olympic Programme.

Finally, this research was able to state that before being multicultural, the Olympic Programme must be composed by universal sports. It also suggests a new method of selecting sports to compose it, based on the accordance of their rules and values to the universalism proposed by the philosophy of Olympism.

\section{DISCUSSION}

\section{Sports and their Rules}

Sport activities were an important part of everyday life in several societies even before the invention of the radio or, later on, the television. Back in the ancient world, when messages used to be transmitted between cities by running men, the Greeks were huge fans of athletics and the Olympic Games, held every four years at the sanctuary of Olympia in honour of Zeus, were the greater festival in the Hellenic World, as said by the lyric poet Pindar. Different cultures in ancient China had also connections to physical activities during their 
existence, varying to a highly developed agricultural people of the south and east that used sport in a peaceful and passive way to groups which practiced exercises as a permanent training for war (Crowther, 2007).

Sports such as athletics, gymnastics, boxing, bull leaping and chariot races were present in all four corners of the ancient world, and each one of them had their own rules. In boxing, for example, it was forbidden clinching, scratching and probably kicking. There were no rounds or other scheduled breaks, no weight classes, and boxers were encouraged to come into contact (Golden, 2004). These regulations could vary from one city to another, and the organizers of each competition were responsible for their establishment and to make every athlete aware of them.

Although sport activities already existed since the Bronze Age and the Minoan civilization back in 3000 BC, sports as known today is a human invention which happened much later in History, after the Industrial Revolution and the Renaissance. The word "sport" is originated from the Old French word "disport" and has been registered for the first time in UK in the 15th century, but its current meaning was assumed only by the end of the 18th century and the beginning of the following century (Melo, 2010). As defended by Parry (2018), the contemporary concept of sport is about a rule-governed and institutionalised contest of human physical skills. Another concept is the one suggested by Meier (1988), who affirms that sport is the demonstration of physical skills and a certain amount of expertise in a goal directed activity that is possible due to accepted rules which limit the permissible means of reaching the task, normally by restricting more efficient in favour of less efficient means.

Regardless of the period in which we look for the notion of sport, rules are an aspect which is always present in the sportive field. From the boxing practiced by the ancient Greeks until the modern football, nowadays the most popular in the world, every single sport is supported by rules in order to define the goals to achieve, to determine both starting and stopping points of the activity and yet to guide in cases where a rule is not followed. Many sporting institutions have also introduced rules to ensure players maintain decorum or certain moral behaviours (Torres, 2014). As a result, scholars have a lot of interest in understanding the functions of each rule in a specific sport and often try to categorize it according to its primary role.

Usually, sport rules are divided between constitutive and regulative. This classification, developed by John Searle in the field of languages but well adapted for this area of knowledge, affirms that constitutive rules are the ones which 'create or define new forms of behaviour, and ... have the form: $X$ counts as $Y$ in context $C$ ', while regulative rules exist mostly to support constitutive rules and to make clear occasions where the predicted goal was successfully achieved (Torres, 2014). Therefore, constitutive rules often define the main task of the game. As example, in the context of weightlifting, a constitutive rule is the one which states that the objective of each athlete is to move the barbell from the platform to the full extent of both arms above the its head, either on the snatch lifting or on the clean and jerk lifting. On the other hand, the existence of two moves on the clean and jerk lifting and the requirement to have both arms and legs fully extended at the end of the movement are examples of regulative rules established by the International Weightlifting Federation in its 2018 IWF Technical and Competition Rules \& Regulations.

There are a number of debates about the definition of categories and its implications. As John Gleaves states in his work Rules, Klaus V. Meier have pointed out that all efforts to categorize game rules may be flawed once that an absolute dichotomization is impossible to be made in a clear way, while William J. Morgan insists that regulative rules are those in which antecedently or independently existing forms of behaviour are regulated (Torres, 2014). Nevertheless, for this essay's discussion, the binary classification of constitutive 
and regulative rules will be accepted and used later on for conclusion and suggestions of possible changes at following Olympic sport programmes.

\section{The Olympic Movement and its Universalism}

The International Olympic Committee and the Olympic Movement emerged during the second half of the 19th century after years of discussions and local events in Western countries such as England, France and Greece. Started by the Frenchman Baron Pierre de Coubertin, nowadays led by the IOC and having the Olympic Charter as set of rules and guidelines for its governance, the Olympic Movement has the goal 'to contribute to building a peaceful and better world by educating youth through sport practised in accordance with Olympism and its values' (IOC, 2019, p. 15).

As pointed out by Parry (2006), this social thinking is a result of Coubertin's perception concerning sports toward the end of the 19th century, and emphasizes the role of sport in global culture, international understanding, peaceful coexistence, and social and moral education. Regarding of the expecting globalization of sports, the Frenchman was right once that nowadays the IOC is a global institution and more than two hundred National Olympic Committees form the Olympic family, whose duty is to promote the Olympic Movement in their respective countries (IOC, 2019).

Among all characteristics connected with the Olympic Movement, perhaps universalism should be the most important, and it is also one of the easiest to be identified on every single activity made by the IOC. If we look particularly at the Olympic Games, the most prominent event organized with the purpose of promoting the philosophy of Olympism, principles of focus not just on elite athletes by the entire humankind, of participation and cooperation, of competition and victory, and others are presented and treated as relevant to the entire world, regardless of nation, race, gender, social class, religion, or ideology. In this sense, the exposure of the universal and unchanging concept of Olympism allows several conceptions of it, depending on where the concept was shown and each society's background (Parry, 2006).

At the same time in which universalism is consider a main attribute of the Olympic Movement, it is also one of the biggest challenges for all institutions that should make efforts to maintain and expand this trend. According to Brownell \& Parry (2012, p. 148), "the Olympic Movement depends on the ideas that give it its significance and meaning". As a consequence of this feature, all actions have the obligation of allowing people coming from very different cultures to extract the values of Olympism from them, a very demanding task to be accomplished. Going back to the example of the Olympic Games, if even at a local level individuals from different age groups react to the same stimulus in distinct ways, the IOC has the hard mission to transform an international event with such a scale into a transmitter of Olympic values.

\section{The Olympic Programme and its Multiculturalism}

The Olympic Programme is the group of all sports competitions established by the IOC for each edition of the Olympic Games, in accordance with the Rule 45 of the Olympic Charter now in force. This plan consists of two components, namely the sports and the events programme. The first includes all sports for a specific edition of the Olympic Games, as determined by the Session from among the sports governed by the International Federations recognised by the IOC, while the other one contains all events which will be held in a specific edition of the Olympic Games, as appointed by the IOC Executive Board. An event is a specific competition in a sport resulting in a ranking giving rise to the award of medals and diplomas (IOC, 2019).

The programme of the previous corresponding edition of the Olympic Games is the starting point for the process of selection sports that will compose the following one. Based upon a review of it, a group consisting 
of the IOC President, four Vice-Presidents and ten other members prepare a proposal, and all voting IOC members should vote and decide on which sports will take part in the edition yet to come of the Olympic Games, in a series of negotiations that occur prior to electing the host city for the aforesaid edition. During the period which starts after the announcement of the host city and ends three years prior to the opening of the relevant Olympic Games, the local organizing committee may propose to the IOC the inclusion, for such edition only, of one or more additional events (IOC, 2019).

At the reinstatement of the Summer Olympic Games in 1896, nine sports were contested. Since then, additions and exclusions of several sports occurred in the following editions and 124 years later, at the Games of the 32nd Olympiad that will be celebrated in Tokyo, 339 events and thirty-three sports will feature the Tokyo 2020 Olympic Programme. More than fifty different sports were at least once an Olympic sport, and the size of the Olympic Programme is a constant care for the IOC and also for organizing committees of each edition. In order to prevent an even bigger event, the Olympic Charter prescribes that an edition of the Games should have no more than ten thousand five hundred athletes, five thousand accredited coaches and athletes' support personnel and three hundred and ten events, unless agreed otherwise with the relevant organizing committee (IOC, 2019).

The inclusion of new sports and events at the Olympic Games also represents an increase of athletes and nations to the event, putting together different cultures. However, as said by McLaughlin \& Torres (2011), in order to transmit the values of Olympism, the Programme must need to improve its global representativeness and inclusion in terms of culture. As participation in the Olympic Games has grown more diverse, the Olympic Programme has been featured predominately by sports coming from Western culture, bringing the Games in line with a kind of thin multiculturalism which includes only the Western part of the world. In practice, this sport homogenization at the biggest event of the IOC allows non-Western societies to have different conceptions of it, creating a situation of thick multiculturalism worldwide (Parry, 2006). For Muslim-majority countries, as example, some women's events are not seen with good eyes and their National Olympic Committees don't send female athletes to compete at then.

Historically, women's events in sports such as wrestling, and weightlifting don't have a large participation of countries in which the majority of the society follows the Islam. At Rio 20016 wrestling competitions, among one hundred and eight athletes divided in six categories, only nine were from these countries. Similar situation happened at weightlifting events, where the same number of women took part, among one hundred and four athletes. As comparison, men's weightlifting events had eighteen Muslim athletes at the same edition of the Games. In both cases, all competitors were at the Olympic Games representing either Egypt, Tunisia or Turkey. Excluding the first one, all these are non-fundamental religious countries, but this level of participation doesn't represent a world's population of almost 2 billion muslins.

\section{CONCLUSIONS}

The current thick multiculturalism of the Olympic Programme does not represent the universalism propagated by the Olympic Movement. In the context of the Olympic Programme, its universalism is the possibility of every single person in the world to watch any event, feel that he/she is being represented by at least one competitor, and finally be able to take the Olympic values out of this experience. In the same context, thin multiculturalism could be seen as athletes coming from all cultures of the world competing and sharing experiences together. As transcribed by MacAloon (2013), De Coubertin's perception on this topic was that 'the true internationalism certainly involved the discovery and experience of social and cultural differences $(\ldots)^{\prime}$. 
Clearly, this worldwide meeting of cultures happens in every edition of the Olympic Games, but it is also evident that in some events of specific sports, it doesn't. Sports are the main raw material for Olympism, and each sport can exemplify one or more values from this philosophy. On the other hand, some of them can also act in the opposite direction and illustrate values of social discrimination and marginalisation. According to internalist theories of sports, each sport expresses its own set of values. Based on that statement, the International Olympic Committee should carefully analyse if each one of the Olympic sports can be used as a way to transmit undesirable values in order to sustain the mission of building a peaceful and better word through sports.

A good way of evaluating the concordance with the Olympic Movement of each sport is doing it by its rules, once that sports are a set of rules and there would be no sport without them (Reid, 2002). A particular sport should not be at the Olympic Programme if it has a constitutive rule that goes against any of the Olympic principles. Simultaneously, sports with regulative rules that follow the same direction must be adjusted to the philosophy of Olympism or, if proved impossible to be done, should be also excluded from the Programme.

At the current Olympic Programme, at least two sports are contradicting the Olympic principle of universalism and their inclusion must be re-discussed. From the formalist perspective, the regulative rule made by the International Federation of Wrestling, known as United World Wrestling, that the cut under the arms shall not exceed 21.5 centimetres in women's uniforms prevents Muslim women to compete at this sport, once the Muslim culture determines that a female person should cover her entire body. In other case, approaching from a theory of sport called Interpretivism, the tradition of leaving both elbows exposed in order to facilitate technical officials' judgements on weightlifting competitions also prevents Muslim women to become weightlifters, although the International Weightlifting Federation that one unitard may be worn under the costume to cover the entire body.

A decision to include or not a specific sport to the Olympic Programme should be based on any person's freedom to compete at it in an edition of the Olympic Games. As said by Reid (2002, p. 71), 'choice is not the result of freedom, freedom is the result of exercised choice', and every single person should be able to choose between participating or not, regardless of his/her home country. If an individual is not allowed to be practitioner of one particular sport and, as consequence, to participate in an Olympic competition because of cultural aspects, this sport is not aligned with the universalism of the Olympic Movement and therefore should not be at the Olympic Programme. Before being multicultural, the Olympic Programme must be composed by universal sports.

\section{REFERENCES}

Brownell, S., \& Parry, J. (2012). Oympic values and ethics in contemporary society. Ghent University Press.

Crowther, N. B. (2007). Sport in Ancient Times. Greenwood Publishing Group.

Golden, M. (2004). Sport in the Ancient World from A to Z. Routledge.

IOC (2019). Olympic Charter. Retrieved June 29, 2019, from International Olympic Committee.

MacAloon, J. J. (2013). This great symbol: Pierre de Coubertin and the origins of the modern Olympic Games. Routledge. https://doi.org/10.4324/9780203819852

Meier, K. (1988). "Triad Trickery: Playing with Sport and Game." Journal of the Philosophy of Sport, XV, 11-30. https://doi.org/10.1080/00948705.1988.9714458

McLaughlin, D., \& Torres, C. R. (2011). A Moral Justification for a More Inclusive Olympic Program. Olympika. The International Journal of Olympic Studies, 20, 55-78. 
Melo, V. A. (2010). Por uma história do conceito esporte: diálogos com Reinhart Koselleck. Revista Brasileira de Ciências do Esporte, 32(1), 41-57. https://doi.org/10.1590/s0101-32892010000400004 Parry, J. (2006). Sport and Olympism: Universals and multiculturalism. Journal of the Philosophy of Sport, 33(2), 188-204. https://doi.org/10.1080/00948705.2006.9714701

Parry, J. (2018). E-sports are Not Sports. Sport, Ethics and Philosophy, 13(1), 3-18.

Reid, H. L. (2002). The philosophical athlete. Carolina Academic Press.

Reid, H. L., \& Austin, M. W. (Eds.). (2012). The Olympics and philosophy. University Press of Kentucky. Torres, C. R. (Ed.). (2014). The Bloomsbury companion to the philosophy of sport. A\&C Black. 